\title{
COMMENTARY
}

\section{Sedation, delirium and psychological distress: let's not be deluded}

\author{
Richard D Griffiths* \\ See related research by Strøm et al., http://ccforum.com/content/15/6/R293
}

\begin{abstract}
New ways of approaching sedation and analgesia are being considered in our endeavour to improve our management of the ventilated patient. Long-term psychological problems are not insignificant and before we can assume benefit or harm of any new approach we must not delude ourselves by using sampling methods that can miss those patients most at risk.
\end{abstract}

\section{Introduction}

Short-term expediency and our own perceptions of distress have usually dominated our sedative approach to mechanical ventilation at the expense of appreciating the long-term consequences of drug exposure, and the effect that unnecessarily prolonged ventilation and immobility might have on neurocognitive function and psychological disorders. Studies have shown that sedative decisions that reduce drug exposure along with daily awakening and weaning of patients may, not surprisingly, reduce ventilation duration $[1,2]$ but also facilitate mobilisation and improve outcomes [3]. One of the first studies suggested less psychological stress [4], particularly reduced post-traumatic stress disorder (PTSD), and was linked to a hypothesis that patients with more amnesia (presumably more cognitive injury) and delusions (altered memory processing) had more PTSD/stress symptoms than those with less amnesia and hence more recall [5]. Despite reducing sedative drug exposure, the weaning trials so far have not been able to show improved neurocognitive outcomes [6], though less delirium was associated with increased mobility [3].

\section{Do we even need sedation?}

Strøm and colleagues [7] suggested that keeping patients more awake by using analgesics only could reduce

*Correspondence: rdg@liverpool.ac.uk

Musculoskeletal Biology, Institute of Ageing and Chronic Disease, Faculty of Health and Life Sciences, University of Liverpool, Liverpool L69 3GA, UK ventilation duration and stay compared with those receiving interrupted sedation in 113 of 140 patients ventilated for more than 48 hours. This was without an increase in complication rates, although agitated delirium was more frequent (or observed?) when sedation was not being used. To address the concern that avoiding sedation completely might itself be a psychological stress, they have followed up these patients in a paper published in Critical Care looking at the longer term psychological consequences [8]. They concluded that their protocol does not increase the risk of psychological problems.

Can we be confident of this assertion from their data? Or are we at risk of deluding ourselves? Of the 113 patients, after 2 years follow-up 70 had died (62\%), leaving only a possible 43 patients eligible to study. Twelve patients did not respond or declined interview so the data are drawn from just 13 in each group. They show similar low depression and anxiety scores and no significant differences in their quality of life measure from this underpowered sample. The neuropsychologist interviewing these patients found no definite cases of PTSD and the symptom stress scores were low in both groups. Both groups of patients from which the data are drawn could recall admission to the ICU and this suggests they have selected out a group of patients with less acute brain dysfunction and amnesia and hence a lower psychological risk. Perhaps they missed those most at risk?

Can we be content that psychological stress is not occurring? As the psychological assessment occurred after almost 2 years we have no knowledge of distress in the 26 patients that survived to leave hospital but died before follow-up. We only have data on $23 \%$ of those ventilated or $60 \%$ of those followed up and alive at 2 years. Superficially this may not seem a problem as there are many published papers, often based upon questionnaires where response rates are similarly reduced to between 60 to $80 \%$ of the population.

\section{Do missing patients matter to an analysis of psychological outcome?}

A key problem is that many researchers inexperienced with the psychological problems of patients following 
intensive care ignore the fact that there are subjects that actively decline interview, do not attend clinics or return a questionnaire. This can significantly distort a psychological analysis. As psychological problems often determine whether patients will agree or not agree to participate, it cannot be assumed that a group of responders is in any way representative of the entire group regarding psychological morbidity. A key symptom of PTSD is avoidance and it is highly probable that patients with PTSD are among those declining to be interviewed. This is such a well recognised concern that careful systematic methods were used following the 2005 London bombings to identify a far higher number of cases needing help for PTSD than in earlier incidences [9].

In striving to understand the harmful consequences of our sedative and analgesic practices in the ICU, much has been learned through identifying the acute brain dysfunction that occurs (manifesting as acute delirium) and its relationship to longer term neurocognitive impairment [10]. However, it is important not to dismiss or ignore the psychological consequences and the distress of delirium associated with frightening delusional experiences in some patients. While heavy sedation use [11] is one risk factor for PTSD, the strongest association with PTSD development is the suffering of frightening delusional experiences [12] and gives an incidence of new PTSD in longer stay patients of $10 \%$. This incidence may be halved by using a patient diary as a specific psychological cognitive therapy after ICU [13]. To be sure of a good neurocognitive outcome it is important to recognize PTSD and address possible specific treatments as it has been shown there are broader benefits, in both alleviating anxiety and depressive symptoms and improving emotional and cognitive function [14], such as executive function [15].

\section{Conclusion}

In critical care sedation research looking to prove an absence of psychological problems one must not miss patients most at risk and similarly in clinical practice after ICU this means not missing the opportunity to treat them.

\section{Abbreviations}

PTSD, post-traumatic stress disorder.

\section{Acknowledgements}

The author wishes to acknowledge Dr Christina Jones and other colleagues in the RACHEL group for their collaborative research over the years.

\section{Competing interests}

The author declares that he has no competing interests.
Published: 16 February 2012

\section{References}

1. Kress JP, Pohlman AS, O'Connor MF, Hall JB: Daily interruption of sedative infusions in critically ill patients undergoing mechanical ventilation. NEngl J Med 2000, 342:1471-1477.

2. Girard TD, Kress JP, Fuchs BD, Thomason JW, Schweickert WD, Pun BT, Taichman DB, Dunn JG, Pohlman AS, Kinniry PA, Jackson JC, Canonico AE, Light RW, Shintani AK, Thompson JL, Gordon SM, Hall JB, Dittus RS, Bernard GR, Ely EW: Efficacy and safety of a paired sedation and ventilator weaning protocol for mechanically ventilated patients in intensive care (Awakening and Breathing Controlled trial): a randomised controlled trial. Lancet 2008, 371:126-134

3. Schweickert WD, Pohlman MC, Pohlman AS, Nigos C, Pawlik AJ, Esbrook CL, Spears L, Miller M, Franczyk M, Deprizio D, Schmidt GA, Bowman A, Barr R, McCallister KE, Hall JB, Kress JP: Early physical and occupational therapy in mechanically ventilated, critically ill patients: a randomised controlled trial. Lancet 2009, 373:1874-1882.

4. Kress JP, Gehlbach B, Lacy M, Pliskin N, Pohlman AS, Hall JB: The long-term psychological effects of daily sedative interruption on critically ill patients. Am J Respir Crit Care Med 2003, 168:1457-1561.

5. Jones C, Griffiths RD, Humphris G, Skirrow PM: Memory, delusions, and the development of acute posttraumatic stress disorder-related symptoms after intensive care. Crit Care Med 2001, 29:573-580.

6. Jackson JC, Girard TD, Gordon SM, Thompson JL, Shintani AK, Thomason JW, Pun BT, Canonico AE, Dunn JG, Bernard GR, Dittus RS, Ely EW: Long-term cognitive and psychological outcomes in the Awakening and Breathing Controlled trial. Am J Respir Crit Care Med 2010, 182:183-191.

7. Strøm T, Martinussen T, Toft P: A protocol of no sedation for critically ill patients receiving mechanical ventilation: a randomised trial. Lancet 2010, 375:475-480.

8. Strøm T, Stylsvig M, Toft P: Long-term psychological effects of a no-sedation protocol in critically ill patients. Crit Care 2011, 15:R293.

9. Brewin CR, Fuchkan N, Huntley Z, Robertson M, Thompson M, Scragg P, d'Ardenne P, Ehlers A: Outreach and screening following the 2005 London bombings:usage and outcomes. Psychol Med 2010, 40:2049-2057.

10. Girard TD, Jackson JC, Pandharipande PP, Pun BT, Thompson JL, Shintani AK, Gordon SM, Canonico AE, Dittus RS, Bernard GR, Ely EW: Delirium as a predictor of long-term cognitive impairment in survivors of critical illness. Crit Care Med 2010, 38:1513-1520.

11. Girard TD, Shintani AK, Jackson JC, Gordon SM, Pun BT, Henderson MS, Dittus RS, Bernard GR, Ely EW: Risk factors for post-traumatic stress disorder symptoms following critical illness requiring mechanical ventilation: a prospective cohort study. Crit Care 2007, 11:R28.

12. Jones C, Bäckman C, Capuzzo M, Flaatten H, Rylander C, Griffiths RD: Precipitants of post traumatic stress disorder following intensive care: a hypothesis generating study of diversity in care. Intensive Care Med 2007, 33:978-985.

13. Jones C, Bäckman C, Capuzzo M, Egerod I, Flaatten H, Granja C, Rylander C, Griffiths RD, and RACHEL Group: Intensive care diaries reduce new onset PTSD following critical illness: a randomised, controlled trial. Crit Care 2010, 14:R168.

14. Kent M, Daavis MC, Stark SL, Stewart LA: A resilience-oriented treatment for posttraumatic stress disorder: results of a preliminary randomized clinical trial. J Traumatic Stress 2011, 24:591-595.

15. Walter KH, Palmieri PA, Gunstad J: More than symptom reduction: Changes in executive function over the course of PTSD treatment. J Traumatic Stress 2010, 23:292-295.

doi:10.1186/cc11176

Cite this article as: Griffiths RD: Sedation, delirium and psychological distress: let's not be deluded. Critical Care 2012, 16:109. 